\title{
催化不对称共轭氰化反应研究进展
}

\author{
周红艳 $*$ 李娜娜 ${ }^{b}$ 杨靖亚 ${ }^{*, b}$ 李天媛 ${ }^{b}$ 李 政 ${ }^{b}$ \\ $\left({ }^{a}\right.$ 甘肃农业大学理学院 兰州 730070) \\ ( ${ }^{b}$ 西北师范大学化学化工学院 兰州 730070)
}

\begin{abstract}
摘要 催化不对称共轭氰化反应是对映选择性构建 $\mathrm{C}-\mathrm{C}$ 键、合成手性 $\beta$-氧基化合物的重要方法, 自 2003 年首次报道 以来备受关注. 近十年来, 对 $\alpha, \beta$-不饱和二酰亚胺、 $\alpha, \beta$-不饱和 $N$-酰基吡咯、 $\alpha, \beta$-不饱和酮、 $\alpha, \beta$-不饱和酷以及硝基烯的 催化不对称共轭氰化反应研究取得了一些重要研究成果. 从金属催化和有机催化两方面、以不同 Michael 受体归类对 这一领域的研究进展进行了综述.
\end{abstract}

关键词 不对称催化; 氨化; Michael 加成; $\alpha, \beta$-不饱和化合物; 过渡金属; 有机催化

\section{Advance in Catalytic Asymmetric Conjugate Cyanation}

\author{
Zhou, Hongyan ${ }^{*, a} \quad$ Li, Nana $^{b} \quad$ Yang, Jingya $^{*, b} \quad$ Li, Tianyuan ${ }^{b} \quad$ Li, Zheng ${ }^{b}$ \\ ( ${ }^{a}$ College of Science, Gansu Agricultural University, Lanzhou 730070) \\ ( ${ }^{b}$ College of Chemistry and Chemical Engineering, Northwest Normal University, Lanzhou 730070)
}

\begin{abstract}
As one of the most important methods to construct $\mathrm{C}-\mathrm{C}$ bond in enantioselective manner and afford optically active $\beta$-cyano compounds, catalytic asymmetric conjugate cyanation reaction has attracted much attentions worldwide since the first report in 2003. Over the past decade, some important achievements have been made in the catalytic asymmetric conjugate cyanation of $\alpha, \beta$-unsaturated imides, $\alpha, \beta$-unsaturated $N$-acylpyrroles, $\alpha, \beta$-unsaturated ketones, $\alpha, \beta$-unsaturated esters, and nitroalkenes. The research progress in this field is reviewed from both metal catalysis and organocatalysis based on different Michael acceptors.
\end{abstract}

Keywords asymmetric catalysis; cyanation; Michael addition; $\alpha, \beta$-unsaturated compounds; transition metals; organocatalysis

有机氰化反应是有机合成中构建 $\mathrm{C}-\mathrm{C}$ 键的重要方 法. 这一领域中, 羰基化合物 ${ }^{[1]}$ 和亚胺 ${ }^{[2]}$ 的不对称氧化 加成因在有机合成中的重要应用得到广泛深入研究. 对 $\alpha, \beta$-不饱和化合物的共轭氰化反应研究则相对较少, 但 反应产物含有多个官能团, 是重要的有机合成中间体, 在生物活性分子 ${ }^{[3 \sim 6]}$ 、天然产物 ${ }^{[711]}$ 及药物 ${ }^{[12 \sim 14]}$ 合成中 具有广泛应用.

早在 20 世纪 40 年代起, 就有关于 $\alpha, \beta$-不饱和化合 物共轭氰化消旋反应的报道, 但其不对称反应研究则起 步较晚. 20 世纪 90 年代, 化学家们报道了以手性噁唑啉 为受体 ${ }^{[15]}$ 或以手性腙为氰基等价体 ${ }^{[16,17]}$ 的不对称共轭 氧基加成反应, 但需要化学计量的手性试剂或助剂. 不
对称催化无疑是不对称合成中最经济、最具挑战性的方 法. 但要同时控制反应中的区域选择性和对映选择性, 使得实现 $\alpha, \beta$-不饱和化合物的催化不对称共轭氰化反应 极具挑战. 2003 年, Jacobsen 等 ${ }^{[13]}$ 首次报道了 $\alpha, \beta$-不饱和 二酰亚胺与三甲基硅氧(TMSCN)的催化不对称共轭加 成反应，拉开了催化不对称共轭氧化反应研究的帷幕. 随后, 化学家们相继报道了 $\alpha, \beta$-不饱和二酰亚胺、 $\alpha, \beta$ 不饱和 $N$-酰基吡咯、 $\alpha, \beta$-不饱和酮、 $\alpha, \beta$-不饱和酯以及 硝基烯的催化不对称共轭氰化反应. 本文从金属催化和 有机催化两方面以不同 Michael 受体分类, 介绍这一重 要反应的研究进展情况.

\footnotetext{
*E-mail: zhouhy@gsau.edu.cn; yangjy@nwnu.edu.cn

Received October 28, 2015; revised November 25, 2015; published online December 4, 2015.

Project supported by the National Natural Science Foundation of China (Nos. 21362034, 21462038), the Research Fund for the Doctoral Program of Higher Education of China (No. 20136203120005), the University Scientific Research Project of Gansu Province (No. 2013B-003) and the Science and Technology Innovation Fund of Gansu Agricultural University (No. GAU-CX1115).

国家自然科学基金(Nos. 21362034, 21462038)、高等学校博士学科点专项科研基金(No. 20136203120005)、甘肃省高等学校科研(No. 2013B-003)和甘 肃农业大学科技创新基金(No. GAU-CX1115)资助项目.
} 


\section{1 金属催化不同 Michael 受体的不对称共轭氧}

\section{化反应}

\section{$1.1 \alpha, \beta$-不饱和二酰亚胺}

2003 年, Jacobsen 等 ${ }^{[13]}$ 报道了首例 $\alpha, \beta$-不饱和羰基 化合物的催化不对称共轭氰化反应(Eq. 1). 作者以 salen-Al ${ }^{\mathrm{III}}$ (1)作催化剂, 实现了 $\alpha, \beta$-不饱和二酰亚胺与 TMSCN 的不对称共轭加成, 应用于 8 种 $\beta$-烷基取代底 物，可以获得 70\% 90\%的产率和 $87 \% \sim 98 \%$ 的 ee 值. 但该法对 $\beta$-不饱和基团(如芳基、乙烯基、炔基)取代的 $\alpha, \beta$-不饱和二酰亚胺不适用. 研究发现, 当单独用 $\mathrm{HCN}$ 作氰源, 没有反应发生, 而使用 TMSCN 和异丙醇原位 生成 HCN 则给出了满意的结果. Jacobsen 应用此法高产 率、高对映选择性地合成了抗惊厥药物普瑞巴林(Pregabalin, 一种 $\beta$-取代- $\gamma$-氨基酸)(Scheme 1)和 $\alpha$-取代- $\beta$-氨 基酸(Scheme 2). 工作的意义不言而喻, 但美中不足的 是催化剂用量较大 $(10 \sim 15 \mathrm{~mol} \%)$, 反应时间较长(26 $48 \mathrm{~h})$.
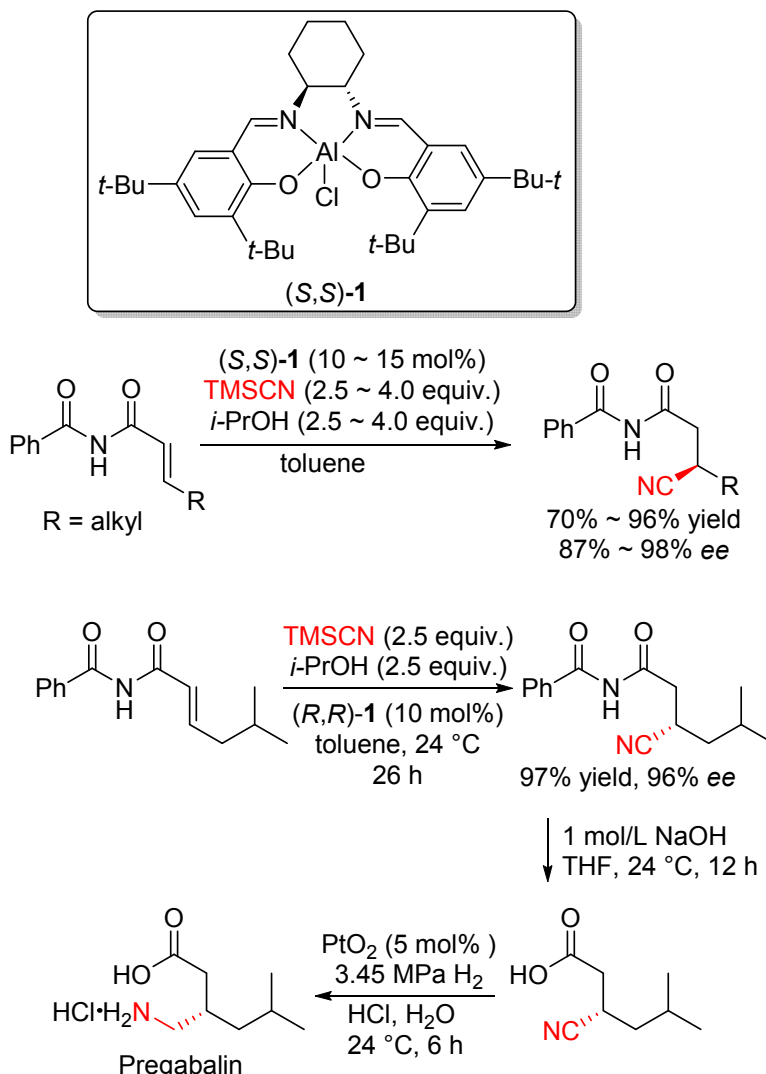

图式 1 普瑞巴林的合成

Scheme 1 Synthesis of pregabalin

机理研究表明, 上述工作中 salen-Al ${ }^{\mathrm{III}}$ (1)作为同双 金属催化剂同时活化二酰亚胺和氰化物. 分析原因, 可 能是铝配合物不能有效活化亲核试剂致使反应活性不 高. 2004 年, Jacobsen 等 ${ }^{[18]}$ 在 2003 年工作的基础上, 设<smiles>CCC[C@H](C#N)CC(=O)NC(=O)c1ccccc1</smiles>

$90 \%$ yield, $96 \%$ ee

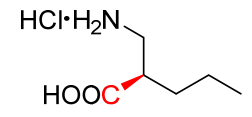

$97 \%$ yield, $94 \%$ ee

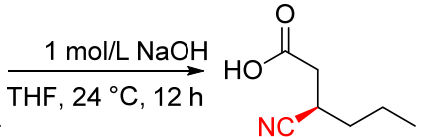

$98 \%$ yield, $96 \%$ ee

DPPA, $\mathrm{NEt}_{3}$ $t-\mathrm{BuOH}, 75^{\circ} \mathrm{C}, 3 \mathrm{~h}$

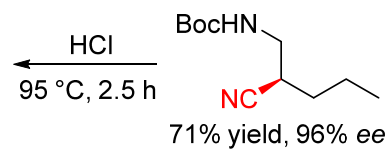

图式 $2 \alpha$-取代- $\beta$-氨基酸的合成

Scheme 2 Synthesis of $\alpha$-substituted- $\beta$-amino acid

计使用杂双金属双催化剂体系手性 $\{($ salen)Al $\}$ 配合物 2 和 $\{($ pybox $) E r\}$ 配合物 3 共同催化 $\alpha, \beta$-不饱和二酰亚胺的 不对称共轭氰化反应(Eq. 2). 其中, 铝配合物活化亲电 试剂不饱和二酰亚胺, 铒配合物活化亲核试剂氧化物. 与之前工作相比较, 催化效果显著提升, 催化剂用量大 幅降低, TMSCN 用量减少, 且反应时间缩短 $(8 \sim 14 \mathrm{~h})$, 产率和 $e e$ 值均有所提升 $(80 \% \sim 94 \%$ 产率，93\% 97\% $e e$ ). 研究表明, 两种催化剂在速率和对映选择决定步骤 协同作用.

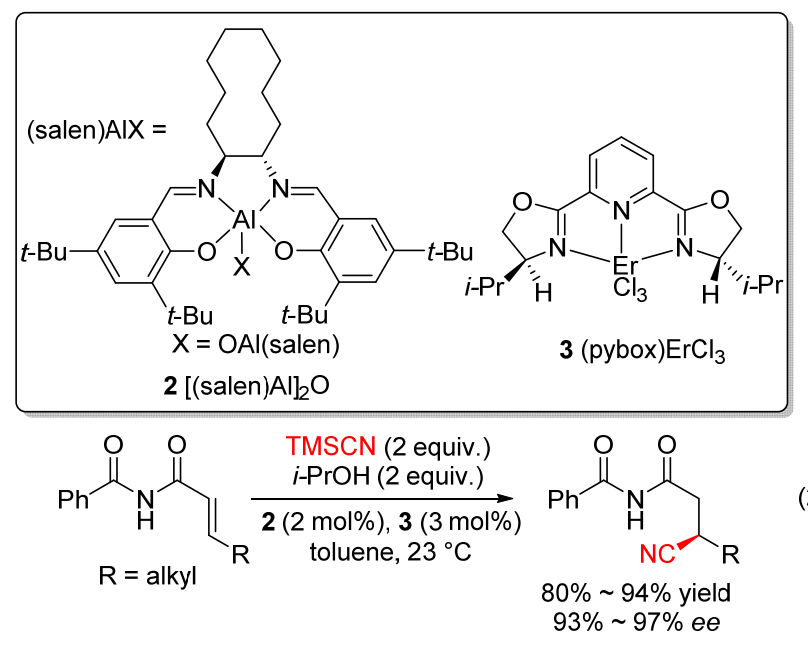

(2)

2008 年, Jacobson 等 ${ }^{[19]}$ 在之前研究基础上，设计合 成了共价键连接的同金属双核 $\{($ salen $) \mathrm{Al}\}$ 催化剂 4, 并 将其应用于 $\alpha, \beta$-不饱和二酰亚胺的催化不对称共轭氰化 反应(Eq. 3). 研究表明, 配合物中的两个铝核分别活化 $\alpha, \beta$-不饱和二酰亚胺和氰化物. 该催化剂与之前催化剂 相比催化活性更高，底物适用范围更广泛. 对 $\mathrm{R}$ 为烷基 的底物, 催化剂用量只需 $2.5 \mathrm{~mol} \%$, 且产率 $(91 \%$ $99 \%)$ 和 $e e$ 值 $(84 \% \sim 96 \%)$ 都非常高. 当 $\mathrm{R}$ 为 $\mathrm{Ph}$ 时，使用 催化剂 1 或上述杂双金属催化剂 $(2+3)$ 均不反应, 但是 在 $5 \mathrm{~mol} \%$ 的同金属双核催化剂 4 作用下，却能以 $65 \%$ 的 产率和 $95 \%$ 的 ee 值得到目标产物, 只是反应时间较长 (72 h). 


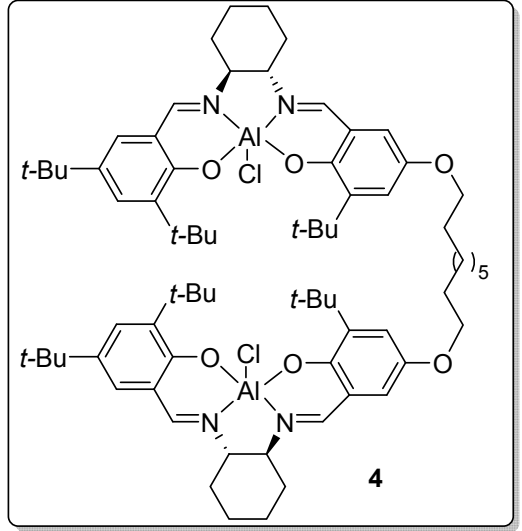

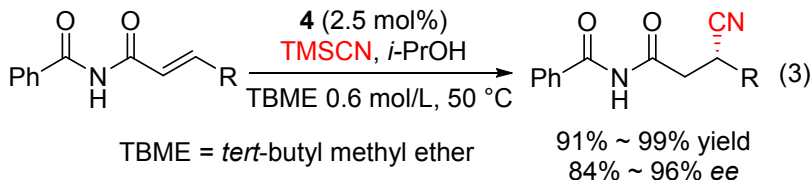

同年, Weck 等 ${ }^{[20]}$ 将 Jacobsen 催化剂 1 支载在聚降冰 片烯上, 合成了催化剂 $\mathbf{5}$, 用于 $\alpha, \beta$-不饱和二酰亚胺的 共轭氰化反应, 获得满意的结果(Eq. 4). 催化剂用量可 以降低至 $5 \mathrm{~mol} \%$, 催化效果依然良好. 催化剂易于分离 回收, 且循环使用 5 次催化活性和对映选择性不减. 动 力学研究表明, 聚合物支载的催化剂 $\mathbf{5}$ 比催化剂 $\mathbf{1}$ 的催 化活性高.
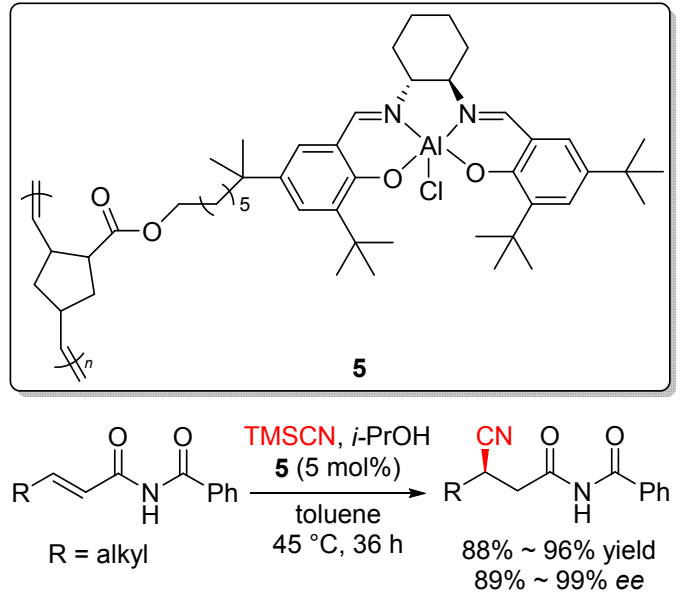

2009 年, Weck 等 ${ }^{[21]}$ 设计合成了交联剂长度和柔性 不同的几种大环环辛烯支载的 AlCl-Salen 催化剂 6 8 (图 1), 并对其在 $\alpha, \beta$-不饱和二酰亚胺 9 的共轭氰化反 应中的催化活性进行了研究.

与 Jacobsen 催化剂 1 相比较, 只需 $5 \mathrm{~mol} \%$ 的催化剂 6 8 就可实现与非支载催化剂 1 相当的实验结果. 研究 进一步表明, 交联剂的长度和柔韧性对催化反应有显著 影响(表 1). 链最长、柔性最好的催化剂 8 具有比 6 和 7 更好的催化活性, 能以最高的产率和 $e e$ 值得到目标产 物 10 .

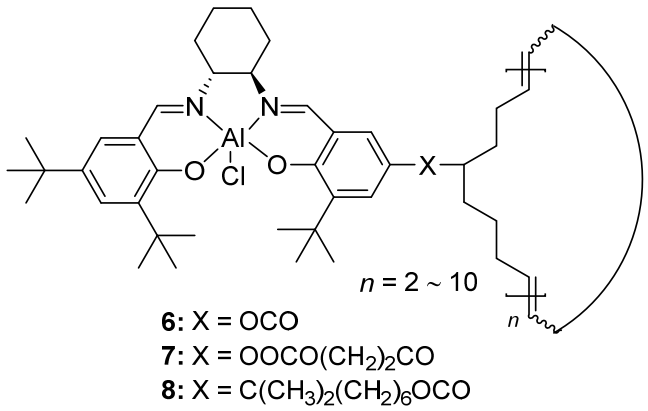

图 1 大环环辛烯支载的 AlCl-Salen 催化剂

Figure 1 Macrocyclic cyclooctene-supported AlCl-Salen catalysts

表 1 支载催化剂中交联剂对 $\alpha, \beta$-不饱和二酰亚胺的不对称共 轭氰化反应的影响

Table 1 Effect of linker on yield and selectivity of the asymmetric addition of cyanide to $\alpha, \beta$-unsaturated imides

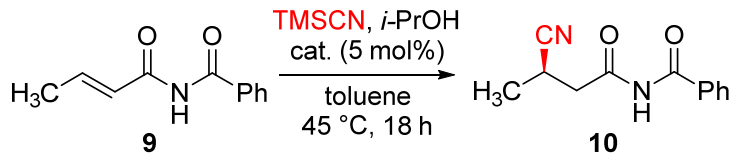

\begin{tabular}{clcc}
\hline Entry & Catalyst & Yield/\% & $e e / \%$ \\
\hline 1 & $\mathbf{6}$ (shorter) & 70 & 93 \\
2 & 7 (medium) & 94 & 82 \\
3 & $\mathbf{8}$ (long) & 98 & 98 \\
\hline
\end{tabular}

\section{$1.2 \alpha, \beta$-不饱和 $N$-酰基吡咯}

2005 年, Shibasaki ${ }^{[14]}$ 首次报道了 $\alpha, \beta$-不饱和 $N$-酰基 吡咯的不对称共轭氰化反应(Eq. 5). 以他们自己设计合 成的 $D$-葡萄糖衍生的手性配体 $\mathbf{1 1}$ 与 $\mathrm{Gd}(\mathrm{O} i-\mathrm{Pr})_{3}$ 原位生 成的配合物作催化剂, 以 $\mathrm{TMSCN}$ 为氧源、 $\mathrm{HCN}$ 作质子 添加剂, 获得 78\% 99\%的产率和 83\% 98\%的 ee 值, 并经此反应简便合成了抗惊厥药物普瑞巴林(Pregabalin)和其它活性分子. 选择适宜的质子添加剂对催化 剂活性和对映选择性有明显的促进作用. 此法可适用于 $\beta$-烷基、 $\beta$-芳基、 $\beta$-环烯基以及 $\alpha, \beta$-二取代的 $\alpha, \beta$-不饱和 $N$-酰基吡咯, 但催化剂用量较大 $(5 \sim 20 \mathrm{~mol} \%)$, 反应时 间很长 $(42 \sim 139 \mathrm{~h})$.

2007 年, Shibasaki 等 ${ }^{[22]}$ 在上述研究的基础上进行了 改进, 设计合成了新配体 12, 并用于催化 $\alpha, \beta$-不饱和 $N$ 酰基吡咯与 TMSCN 的共轭氰基加成(Eq. 6). 质子添加 剂 2,6-二甲基苯酚对反应有显著促进作用. 研究表明, 虽然配体 11 和 12 均与 $\mathrm{Gd}(\mathrm{O} i-\mathrm{Pr})_{3}$ 形成了自组装的多金 属配合物, 但 12 的钝配合物具有更为稳定的高阶结构, 其催化活性更高. 与之前工作相比, 反应速率加快, 反 应时间缩短至 $1 \sim 38 \mathrm{~h}$, 催化剂用量可减少至 $2 \sim 10$ $\mathrm{mol} \%$ ，并保持高的产率( $89 \% \sim 99 \%)$ 和 ee 值( $86 \%$ 96\%). 有意思的是，手性相同的配体 12 和 11, 反应的对 


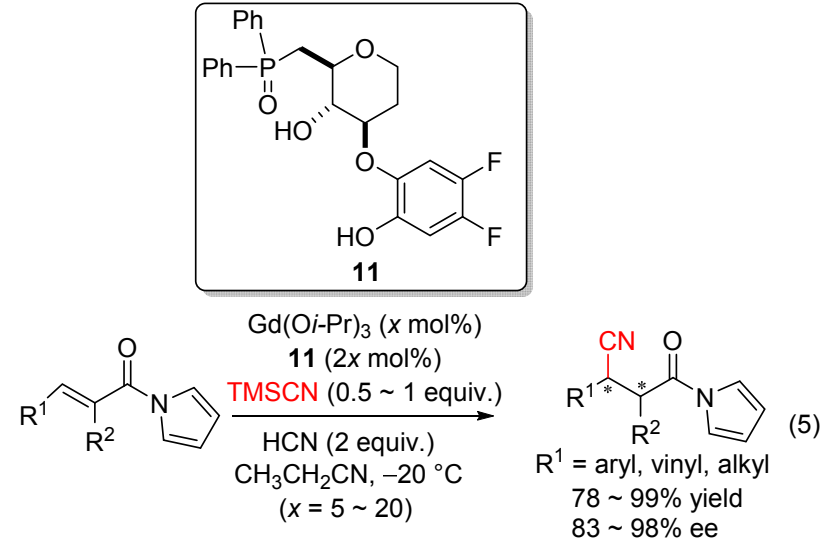

映选择性却相反. 配体小的结构变化在多金属催化剂的 高阶结构中得以放大, 导致不对称催化剂作用的戏剧性 变化.
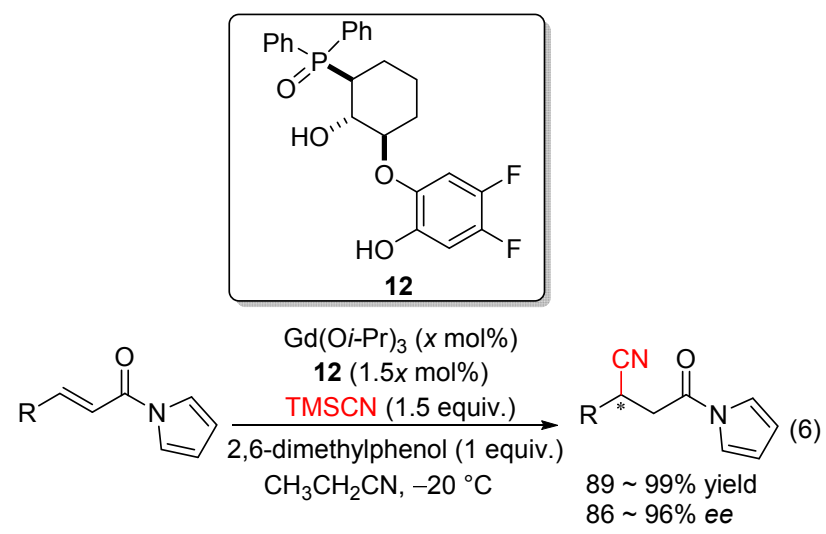

2009 年, Shibasaki 等 ${ }^{[23]}$ 用上述配体 12 的钝配合物 催化 $\alpha$-烷基或芳基取代的 $\alpha, \beta$-不饱和 $N$-酰基吡咯的共 轭氢氰化反应, 得到了利用不对称 $\alpha$-烷基化或芳基化难 以得到的 $\alpha$-手性产物(Scheme 3). 反应时间 1 96 h, 获 得 $82 \% \sim 99 \%$ 的产率和 $80 \% \sim 91 \%$ 的 $e e$ 值. 认为反应经 共轭氰化-对映选择性质子化过程, 由烯醇硅醚转金属 形成关键中间体烯醇化钝为反应决速步骤.

不对称催化构建手性季碳中心是有机合成中一项 重要而又极具挑战的工作. Shibasaki 等将上述配体 12 的 钝配合物用来催化 $\beta, \beta$-二取代的 $\alpha, \beta$-不饱和 $N$-酰基吡咯 的共轭氰化反应, 只以很低的产率和对映选择性得到目 标产物. 将金属换作碱土金属锶, 虽然能使产率和对映 选择性明显提高, 但仍然不尽人意. 2010 年, Shibasaki 等 ${ }^{[24]}$ 改变配体 12 中的膦氧基团为醚单元, 设计合成了 带有二(对甲苯基)甲基异丁基醚基团的新配体 13, 它与 $\mathrm{Sr}(\mathrm{O} i-\mathrm{Pr})_{2}$ 原位生成的配合物能有效催化 $\beta, \beta$-二取代的 $\alpha, \beta$-不饱和 $N$-酰基吡咯的共轭氧化反应(Eq. 7). 将氧源 由 $\mathrm{TMSCN}$ 换作 $\mathrm{TBSCN}$, 可使催化剂用量大幅减少 $(0.5 \sim 10 \mathrm{~mol} \%)$. 实验结果表明, $(E)$-型和 $(Z)$-型底物得 到构型相反的对映体产物.

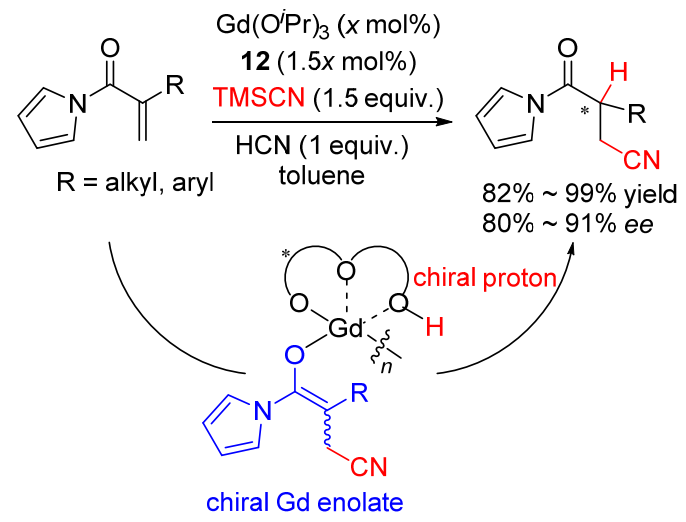

图式 $3 \alpha$-取代的 $\alpha, \beta$-不饱和 $N$-酰基吡咯的共轭氰化-对映选 择性质子化反应

Scheme 3 Catalytic conjugate cyanation-enantioselective protonation of $\alpha$-substituted $\alpha, \beta$-unsaturated $N$-acylpyrroles
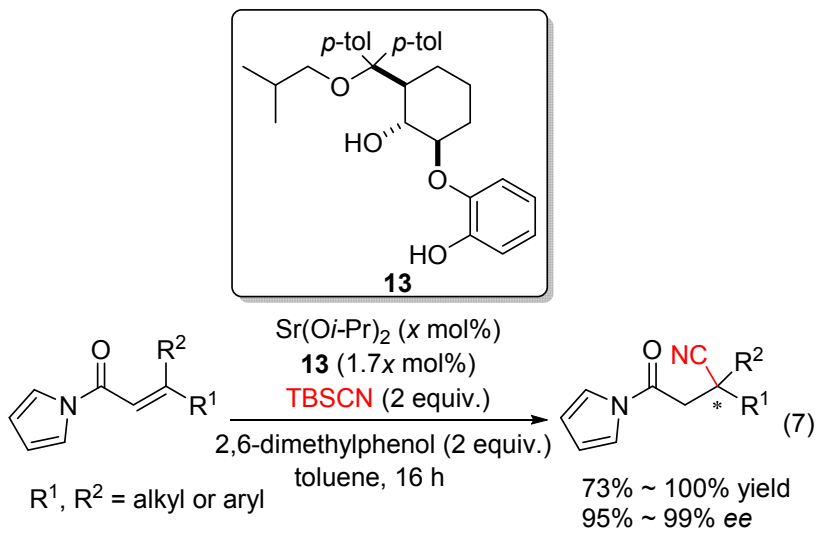

尽管 Jacobson 催化剂 1 4 和 Shibasaki 催化体系 $11 \sim 13$ 的钝或锶配合物分别在催化 $\alpha, \beta$-不饱和二酰亚胺 和 $\alpha, \beta$-不饱和 $N$-酰基吡咯的共轭氧化反应中取得重大 突破, 但其最高转换数(TON)分别只能达到 50 和 200 . 2014 年, Ohkuma 等 ${ }^{[25]}$ 将其开发的手性 Ru-Li 组合催化 剂[26]用于催化 $\alpha, \beta$-不饱和 $N$-酰基吡咯的不对称共轭氧 化反应，底物与催化剂物质的量比高达 200 2000 (Eq. $8)$. 在手性 $\operatorname{Ru}[(S) \text {-phgly }]_{2}[(S)$-binap $](\mathbf{1 4}$, phgly $=$ phenylglycinate)与非手性的 $\mathrm{CH}_{3} \mathrm{OLi}$ 组合催化剂作用下，直接 以 $\mathrm{HCN}$ 为氧源, $\beta$-烷基和 $\beta$-杂原子取代烷基- $\alpha, \beta$-不饱 $N$-酰基吡咯在叔丁基甲基醚(TBME)中反应 $13 \sim 72 \mathrm{~h}$, 能以 $90 \%$ 以上的产率和 $88 \% \sim>99 \%$ 的 $e e$ 值得到目标 产物. 这也是目前为止 $\alpha, \beta$-不饱和 $N$-酰基吡咯不对称共 轭氰化反应中 TON 最高的一例报道.

\section{$1.3 \alpha, \beta$-不饱和酮}

虽然对 $\alpha, \beta$-不饱和二酰亚胺和 $\alpha, \beta$-不饱和 $N$-酰基吡 咯的催化不对称共轭氧化反应取得了重大进展，但对 $\alpha, \beta$-不饱和酮的催化不对称共轭氰化反应研究起步较 晚. 因为 $\alpha, \beta$-不饱和酮在氰化反应中存在两可性: 既可 以发生 1,2-加成, 又可以发生 1,4-加成. 因此, 要实现其 


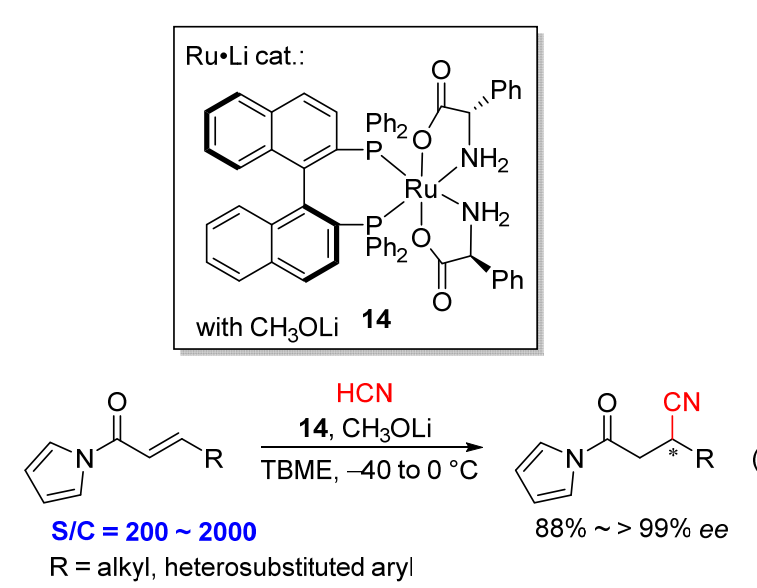

不对称共轭氰化反应, 既要控制区域选择性, 又要控制 对映选择性, 而对两者中任何一个因素的控制都比较困 难.

2008 年, Shibasaki 等 ${ }^{[27]}$ 在前期研究基础上, 首次成 功实现了 $\alpha, \beta$-不饱和酮的不对称共轭氰化反应(Eq. 9).

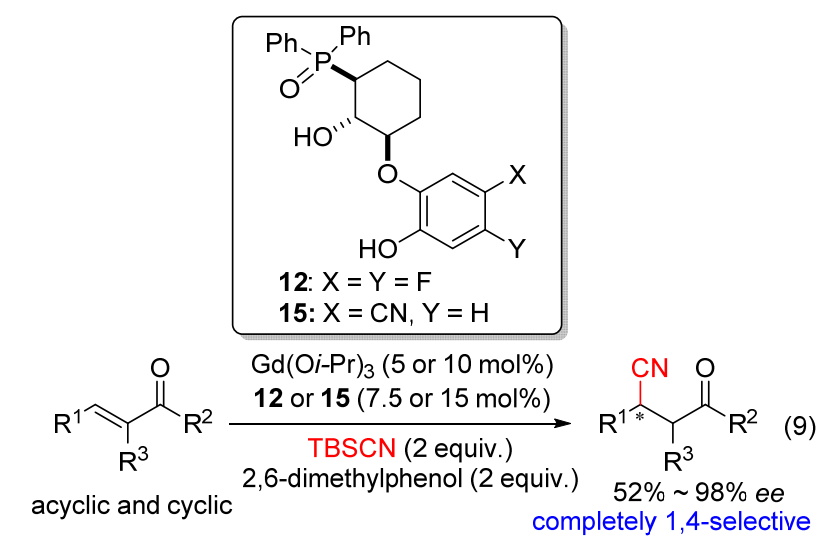

实验研究发现: (1)配体选择对反应的区域选择性影 响显著. 当不加入质子添加剂时, 使用配体 11 , 得到的 是 1,2-加成产物, 而用配体 12, 则能以近似 $1: 1$ 的比率 得到 1,2-和 1,4-加成产物(Table 2, Entries 1,2). (2)质子添 加剂对反应区域和对映选择性有明显促进作用. 加入 $\mathrm{HCN}$ 没有改变反应速率, 反而降低了反应的 1,4-选择性 (Table 2, Entry 3). 而加入与 TMSCN 等物质的量的质子 添加剂 2,6-二甲基苯酚(DMP), 则完全得到 1,4-加成产 物, 且对映选择性大幅提升(Table 2, Entry 4). (3)虽然 TMSCN 在反应条件下完全转化为 $\mathrm{HCN}$, 但加入纯的 $\mathrm{HCN}$ 时反应的区域和对映选择性都很差(Table 2, Entry 5 vs 4). 而且, 当用 TBSCN 代替 TMSCN 作氰源, 产率 和 $e e$ 值均有所提高(Table 2, Entry 6 vs Entry 4). 表明氰 源中的硅基团对反应速率、区域选择性和对映选择性影 响显著.

机理研究表明, 在前述 $\alpha, \beta$-不饱和 $N$-酰基吡咯的共 轭氢氰化反应中 ${ }^{[14,22,23]}$, 活性催化剂是具有高阶结构的
表 2 配体和反应条件对 $\alpha, \beta$-不饱和酮的不对称共轭氰化反应 影响

Table 2 Effects of ligand and conditions on the asymmetric conjugate addition of cyanide to $\alpha, \beta$-unsaturated ketones

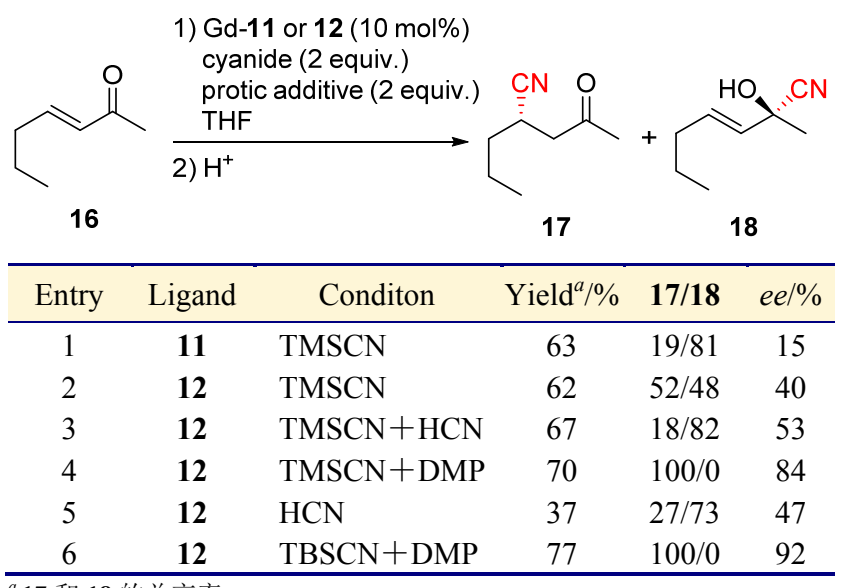

${ }^{a} 17$ 和 18 的总产率.

含质子的多金属配合物 19 (图 2), 而在 $\alpha, \beta$-不饱和酮的 共轭氢氰化反应中, ESI-MS 研究显示优化反应条件下 催化剂为 $O$-叔丁基二甲基硅基化的配合物 21, 这也和 硅基团对反应速率、区域选择性和对映选择性影响显著 的实验结果一致. 与含质子配合物 19 相比, 硅基化配合 物 21 是更为有效的 1,4-选择性催化剂. 使用 TBSCN 时 形成的配合物 21 含有比使用 TMSCN 时形成的配合物 20 更大的硅基团，因而使硅基化的 1,4-选择性催化剂更 为稳定.

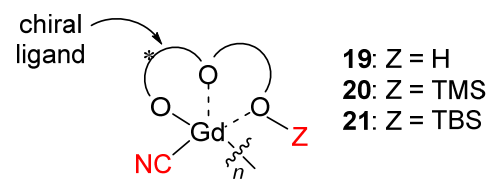

图 2 不对称催化剂

Figure 2 Asymmetric catalysts

另外, 实验研究发现外消旋的 1,2-加成产物 18 在优 化反应条件下能够对映选择性地转化为相应 1,4-加成产 物 17, 而不加催化剂则没有反应发生. 这一结果表明: 本反应专一的区域选择性地获得依赖于催化条件下 1,2加成的可逆性和 1,4-加成的不可逆性, 部分生成的 1,2加成产物在催化反应条件下最终全部转化为 1,4-加成产 物.

2010 年, Shibasaki 等 ${ }^{[24]}$ 利用其新配体 $\mathbf{1 3}$ 与 $\mathrm{Sr}(\mathrm{O} i-$ $\operatorname{Pr})_{2}$ 原位生成的配合物, 不仅能有效地催化 $\beta, \beta$-二取代 的 $\alpha, \beta$-不饱和 $N$-酰基吡咯的共轭氰化反应, 此催化体系 对 $\beta, \beta$-二取代的 $\alpha, \beta$-不饱和酮底物同样具有优越的催化 性能, 实现了手性季碳中心的构建(Eq. 10). 以低于 1 $\mathrm{mol} \%$ 的催化剂用量，就能获得很高的产率和对映选择 性. $(E)$ 型和 $(Z)$ 型底物得到构型相反的对映体产物. 与上 
述相同的原因，所有底物均区域选择性专一地转化为 1,4-加成产物.

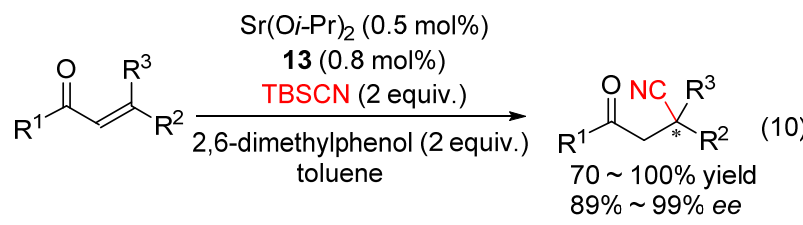

Shibasaki 工作中底物仅限于脂肪类 $\alpha, \beta$-不饱和酮, 不适用于芳香类 $\alpha, \beta$-不饱和酮, 且反应时间较长 $(1 \sim 24$ h). 陈甫雪课题组受其之前建立的碱金属盐催化 $\alpha, \beta$-不 饱和酮的共轭氰化方法 ${ }^{[28 ~ 30]}$ 启发, 于 2010 年报道了首 例无过渡金属催化的 $\alpha, \beta$-不饱和酮的共轭氰化反应策略 (Eq. 11 $)^{[31]}$. 用 $(R)-6,6^{\prime}$-二金刚烷基取代的联菱磷酸与 $\mathrm{NaOH}$ 原位生成的手性磷酸钠盐 $(R)-\mathbf{2 2}$, 成功地催化了 一系列查尔酮衍生物与 $\mathrm{TMSCN}$ 的不对称共轭氰化反 应. 反应时间短 $(0.5 \sim 3 \mathrm{~h})$ 、产率高 $(86 \% \sim 96 \%)$ 、区域选 择性专一, 但遗憾的是催化剂用量较大 $(20 \mathrm{~mol} \%)$, 且只 能得到 $50 \% \sim 72 \%$ 的 $e e$ 值.
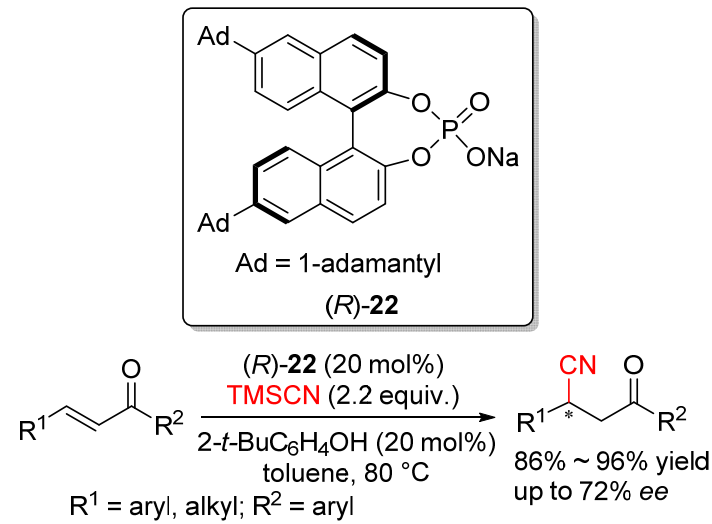

Shibasaki 和陈甫雪课题组的研究工作各具特色, 但 美中不足的是反应的 TON 不高, 分别为 $10 \sim 100$ 和 5 . 2011 年, Ohkuma 等 ${ }^{[32}$ 将其开发的手性 Ru-Li 组合催化 剂用于催化 $\alpha, \beta$-不饱和酮的不对称共轭氰化反应. 直接 以 $\mathrm{HCN}$ 为氧源, 在 14- $\mathrm{C}_{6} \mathrm{H}_{5} \mathrm{OLi}$ 组合催化剂作用下, 底 物与催化剂物质的量比高达 $200 \sim 1000$ (Eq. 12). 一系 列 $\alpha, \beta$-不饱和酮在 TBME 中反应 $2 \sim 47 \mathrm{~h}$, 能以 $80 \%$ $99 \%$ 的产率和 $82 \% \sim 98 \%$ 的 $e e$ 值得到目标产物, 底物耐 受性较好. 这也是目前为止 $\alpha, \beta$-不饱和酮不对称共轭氰 化反应中 $\mathrm{TON}$ 最高的一例报道.

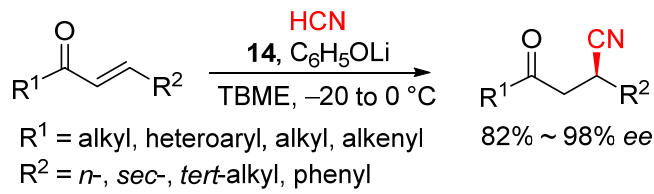

$\mathrm{S} / \mathrm{C}=200 \sim 1000$
2013 年, 陈甫雪课题组在其前述研究 ${ }^{[31}$ 基础上, 对 其无过渡金属催化的 $\alpha, \beta$-不饱和酮的共轭氰化反应策略 进行改进. 以手性磷酸钠盐 $(S)-22$ 作催化剂, 不同的是 将碱由 $\mathrm{NaOH}$ 换为 $\mathrm{NaNH}_{2}$ 、将氰源由 $\mathrm{TMSCN}$ 换作二苯 甲酮氯醇，反应对映选择性得到大幅提升( $92 \%$ ～98\% $e e$ ), 且催化剂用量可降低至 5 $10 \mathrm{~mol} \%$ (Eq. 13). 催化 剂手性相反，所得产物构型也相反 ${ }^{[33]}$.

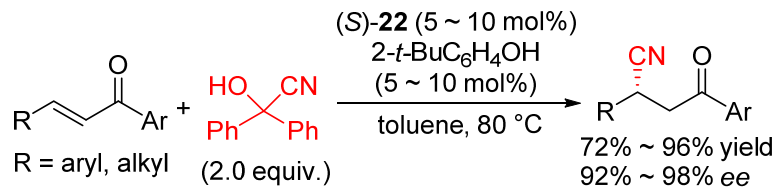

碱土金属是地球上最为常见的元素，与过渡金属相 比，其含量丰富且相对无毒. 2014 年, 王锐课题组 ${ }^{[34]}$ 首 次使用手性 $\mathrm{Mg}$ 配合物成功催化了 $\alpha, \beta$-不饱和酰胺及 $\alpha, \beta$-不饱和䣶的不对称共轭氰化反应(Scheme 4). 在 20 $\mathrm{mol} \%$ 的配体 23 与 $\mathrm{Bu}_{2} \mathrm{Mg}$ 形成的单核催化剂作用下，以 $\mathrm{TMSCN}$ 为氯源, 实现了 $\alpha, \beta$-不饱和酰胺的共轭氰化反 应, 得到最高 $82 \%$ 的 $e e$. 研究发现, 在 $\alpha, \beta$-不饱和酰胺 反应体系中加入质子添加剂反而得不到氰化加成产物. 将催化剂 $23 / \mathrm{Bu}_{2} \mathrm{Mg}$ 用于 $\alpha, \beta$-不饱和酮底物, 表现出很 低的催化活性和立体选择性. 但是, 用配体 $\mathbf{2 4}$ 与 $\mathrm{Bu}_{2} \mathrm{Mg}$ 形成的双核催化剂催化 $\alpha, \beta$-不饱和酮的共轭氰化，却能 高产率、高对映选择性地获得目标产物. 质子添加剂在 两种底物中的作用完全不同, 在 $\alpha, \beta$-不饱和酮的氧化反 应中加入 2,6-二叔丁基苯酚, 能极大地促进反应产率和 对映选择性的提高.

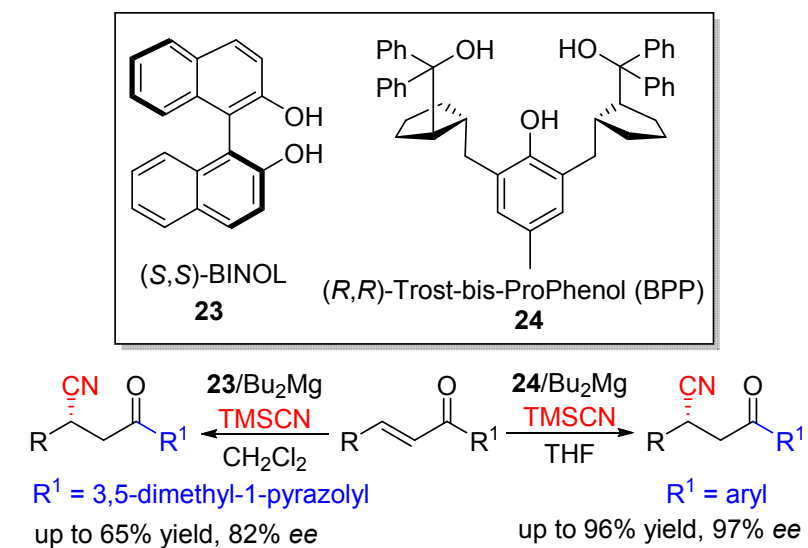

图式 $4 \mathrm{Mg}$ 催化 $\alpha, \beta$-不饱和酰胺、酮的不对称共轭氧化反应 Scheme 4 Magnesium complexes catalyzed asymmetric conjugate cyanation of $\alpha, \beta$-unsaturated amides and ketones

\section{$1.4 \alpha, \beta$-不饱和酯}

与上述 Michael 受体相比较, $\alpha, \beta$-不饱和酯的反应活 性较低. 2010 年, 冯小明课题组 ${ }^{[35]}$ 将其开创的组合催化 体系成功应用于亚烷基丙二酸二乙酯的不对称共轭氰 
化反应(Eq. 14). 这是催化 $\alpha, \beta$-不饱和酯不对称共轭氰化 反应的首例报道.

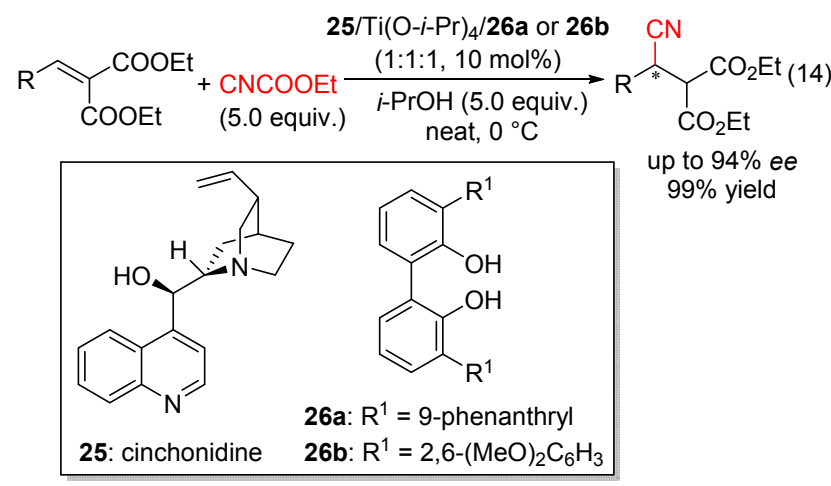

在手性辛可尼丁 25、 $\mathrm{Ti}(\mathrm{O}-i-\mathrm{Pr})_{4}$ 和非手性的 3, $3^{\prime}$-二 取代的联苯二酚 $26 \mathrm{a}$ 或 $26 \mathrm{~b}$ 等物质的量比的组合催化剂 作用下, 以相对廉价、低毒的氰甲酸乙酯为氰源, 在无 溶剂条件下反应 $72 \mathrm{~h}$, 一系列亚烷基丙二酸二乙酯高产 率、高对映选择性地转化为相应目标产物. 该法催化剂 易得, 反应条件温和, 底物适用广泛. 这也是迄今为止 唯一一例金属催化 $\alpha, \beta$-不饱和酯的不对称共轭氰化反应 报道.

\section{5 硝基烯}

硝基烯作为一种强的 Michael 受体, 它的不对称共 轭氰化反应是合成手性 $\beta$-硝基腈的最直接、最简单的途 径. 但这一反应看似简单, 实则不然, 因为硝基烯在碱 性条件下极易聚合.

最早报道的硝基烯的催化不对称共轭氧化反应方 法是使用相转移催化剂(PTC)的有机催化策略 ${ }^{[36,37]}$, 但 都存在催化效率不高、反应时间长的问题.

王锐课题组认为: $\beta$-芳基硝基烯稳定的离域特性和 Michael 受体片段低极化的特点, 导致其在共轭氭化反 应中表现出较低的反应活性; 而 $\beta$-烷基硝基烯因为没有 芳环去构建一个大的离域体系，与 $\beta$-芳基硝基烯相比， 其共轭体系更容易被破坏; 因此, 认为烷基硝基烯极化 程度高且缺乏芳香离域, 是共轭氰化反应理想的 Michael 受体.

基于上述理解, 2012 年王锐课题组 ${ }^{[38]}$ 对 $\beta$-烷基硝基 烯的共轭氰化反应进行了研究(Scheme 5). 在 $20 \mathrm{~mol} \%$ Salen 配体(27)与 $\mathrm{Ti}(\mathrm{O}-i-\mathrm{Pr})_{4}$ 原位生成的 Salen-Ti 催化剂 存在下, 在甲苯中于 $-40 \sim-15{ }^{\circ} \mathrm{C}$ 反应 $8 \sim 15 \mathrm{~h}$, 链状 和环状硝基烯均能顺利转化, 以 $44 \% \sim 90 \%$ 的产率和 $46 \% \sim 84 \%$ 的 $e e$ 值得到目标产物. 反应不需要额外添加 质子添加剂. 当反应温度提高至室温时, 反应一般只需 $10 \mathrm{~min}$ 就可以完成, 但产率和对映选择性略有下降. 这 是第一例金属催化的硝基烯的不对称共轭氰化反应，但 催化剂用量大，获得较高对映选择性的温度较低.

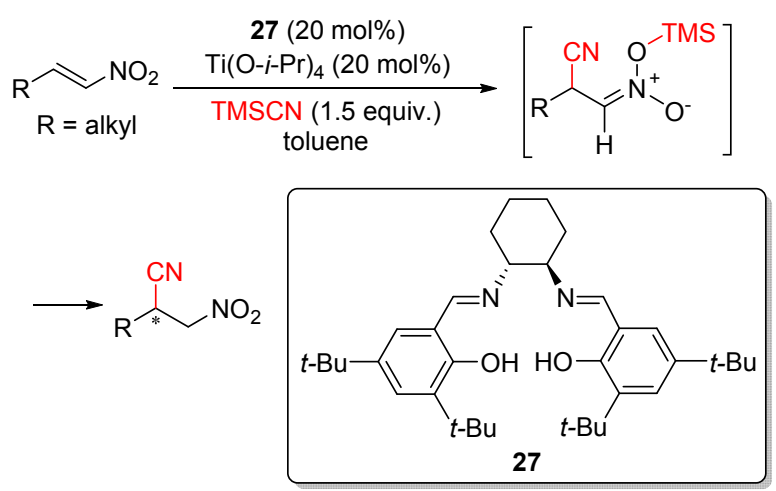

图式 5 Salen-Ti 催化硝基烯的不对称共轭氰化反应 Scheme 5 Salen-Ti complexes catalyzed asymmetric conjugate cyanation of nitroalkenes

2013 年, North 等 ${ }^{[39]}$ 使用由配体 27 预先制备分离得 到的 Salen-Ti(IV)双金属配合物或 Salen-V(V)配合物催 化 $\beta$-烷基硝基烯的不对称共轭氰化反应，在甲苯中于 $0{ }^{\circ} \mathrm{C}$ 反应，就能以高达 $100 \%$ 的转化率和 $79 \% \sim 89 \%$ 的 $e e$ 值得到目标产物(Eq. 15). 与王锐原位制备的 Salen-Ti 催化剂相比, 催化活性更高, 催化剂用量(2 mol\%或 3 $\mathrm{mol} \%$ )大幅降低, 且反应条件更为温和.

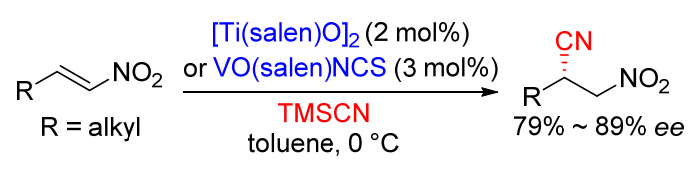

2014 年, Khan 等 ${ }^{[40]}$ 使用 $5 \mathrm{~mol} \%$ 的 salen- $\mathrm{Al}^{\mathrm{III}}$ 催化剂 $(R, R)-1$ 催化 $\beta$-烷基硝基烯的不对称共轭氰化反应，以 4苯基吡啶 $\mathrm{N}$-氧化物(4-PPNO)作添加剂, 在甲苯中于一 $15{ }^{\circ} \mathrm{C}$ 反应，能以 $81 \% \sim 93 \%$ 的产率和 $76 \% \sim 90 \%$ 的 $e e$ 值得到目标产物 $\beta$-硝基腈(Eq. 16). 机理研究表明, 添加 剂 4-PPNO 兼具轴向配体和活化氰源 TMSCN 的双重作 用，从而提高反应活性.

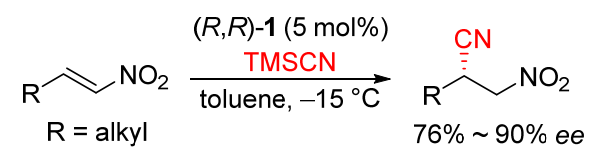

\section{2 有机催化的不对称共轭氧化反应}

有机催化 ${ }^{[41]}$ 自 2000 年复兴以来, 因具有反应条件 温和、操作简便、催化剂无毒易得等优点得以迅速发展, 大量具有不同活化模式和反应活性的有机催化剂被设 计合成出来，并成功应用于多种反应的不对称催化过 程. 有机催化成为继酶催化和过渡金属催化之后的第三 类极具竞争力和潜力的不对称催化方法, 并在手性药物 合成应用中初露锋芒 ${ }^{[42]}$.

有机催化不对称共轭氰化反应的最早报道始于 2008 年, 至今也只有五例报道, 所用催化剂均为手性相 
转移催化剂 ${ }^{[43]}$.

2008 年, Ricci 和 Fochi 等 ${ }^{[36]}$ 以 $\beta, \beta^{\prime}$-二取代的硝基烯 为 Michael 受体, 丙酮氰醇为氰源, 报道了首例有机催 化的不对称共轭氧化反应(Eq. 17). 理论上氢键催化剂 脲或者硫嫝能通过氢键活化硝基烯, 但实验结果表明这 两类催化剂在硝基烯的共轭氰化反应中没有催化活性, 而金鸡纳碱衍生的季铵盐 28 却能给出较为满意的结果. 在 $10 \mathrm{~mol} \%$ 相转移催化剂 28 作用下, $\beta, \beta^{\prime}$-二取代的硝基 烯能够顺利转化, 得到含手性季碳中心的 $\beta$-硝基腈产 物. 但是, 由于 $\beta, \beta^{\prime}$-二取代的硝基烯在无机碱 $\mathrm{K}_{2} \mathrm{CO}_{3}$ 存 在下部分异构化为非共轭的硝基烯, 目标产物产率不 高. 此外, 反应时间长 $(72 \mathrm{~h})$, 对映选择性不尽人意.
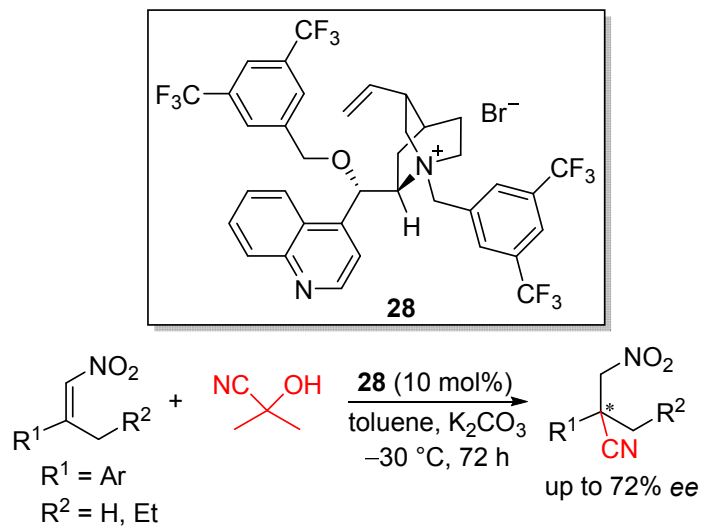

2010 年 Lassaletta 和 Fernández 等 ${ }^{[37]}$ 认为, 以 TMS$\mathrm{CN}$ 为氭源与硝基烯反应，生成中间体 $\beta$-氭基氮酸硅烷 基酯，从而避免碱性条件下的副反应硝基烯的聚合. 对 几种不同催化剂的考察发现, 对于硝基烯与 TMSCN 的 共轭氰化反应，单一的硫脲或金鸡纳碱没有或只有很低 的催化活性, 而结合金鸡纳碱和硫艮两个单元的双功能 催化剂能给出较好的反应结果, 但效果最好的当属含硫 嫝单元的金鸡纳碱衍生的相转移催化剂 29 (Scheme 6). 另外, 催化剂阴离子对催化活性影响显著, 用㲵根离子 代替卤阴离子, 能有效促进反应活性和对映选择性. 研 究工作对有机催化的这一反应具有重要指导意义, 但仍 然存在反应温度低 $\left(-78 \sim-20{ }^{\circ} \mathrm{C}\right)$ 、反应时间长 $(20 \sim$ $96 \mathrm{~h}$ )的不足.

2011 年, Deng 等 ${ }^{[44]}$ 首次报道了有机催化的 $\alpha, \beta$-不饱 和酮和 $\alpha, \beta$-不饱和 $N$-酰基吡咯的共轭氰化反应(Eq. 18). 碱存在下, 以丙酮氰醇为氭源, 在 $10 \mathrm{~mol} \%$ 相转移催化 剂 30 或 31 作用下, 成功实现了 $\alpha, \beta$-不饱和酮、 $\alpha, \beta$-不饱 和 $N$-酰基吡咯的不对称共轭氰化反应, 高产率、高对映 选择性地得到目标产物. 使用构型相反的催化剂 30 和 31, 能分别得到两个对映异构体产物. 催化剂结构研究 表明，9-位和季氮上大位阻的取代基能显著促进反应的 立体选择性. 在 $\alpha, \beta$-不饱和 $N$-酰基吡咯的反应中, 以

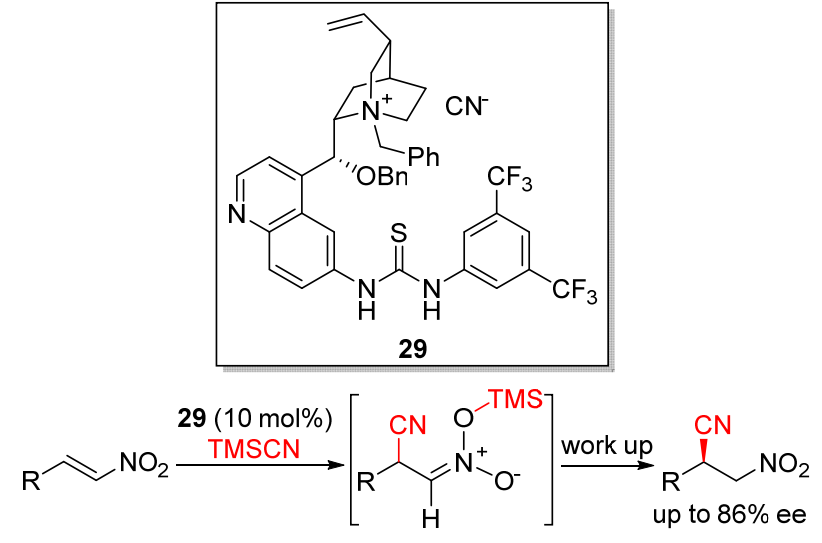

图式 6 含硫嫝单元的手性相转移催化体系

Scheme 6 Chiral PTC catalyst integrating thiourea fragment
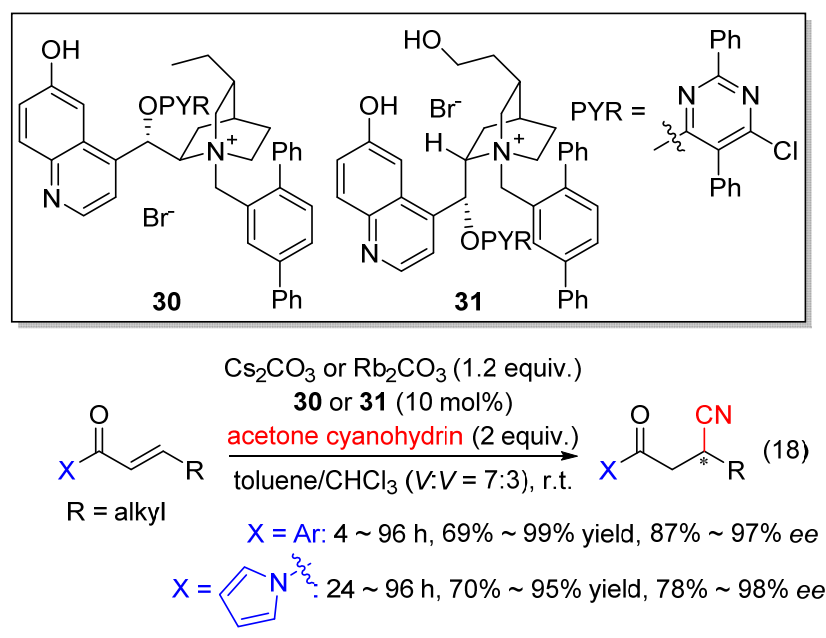

$\mathrm{Rb}_{2} \mathrm{CO}_{3}$ 替代 $\mathrm{Cs}_{2} \mathrm{CO}_{3}$, 反应效果更好. 此外, 在 $\alpha, \beta$-不饱 和酩的反应中没有检测到 1,2-加成产物，所有底物均区 域选择性专一地转化为 1,4-加成产物.

2012 年, Shibata 等 ${ }^{[45]}$ 以丙酮氰醇为氰源, 对 $\beta$-芳 基- $\beta$-三氟甲基二取代的 $\alpha, \beta$-不饱和酮的不对称共轭氰 化反应进行了研究，高效构建了三氟甲基化的手性季碳 中心(Eq. 19). 对于该反应来说，着基型金鸡纳碱衍生的 相转移催化剂没有对映选择性，而对羟基进行保护的相 应醚型催化剂 32 却表现出很高的催化效率. 在以异丙 醚为溶剂的高稀反应体系中, 高产率、高对映选择性地 得到目标产物. 有意思的是, 使用 $\mathrm{Cs}_{2} \mathrm{CO}_{3}$ 或 $\mathrm{K}_{2} \mathrm{CO}_{3}$ 作 碱, 几乎定量地得到 1,4-加成产物, 而使用 $\mathrm{NaOH}$ 或 $\mathrm{NaOEt}$, 则只能得到 1,2-加成产物. 另外, 利用反应所得 产物, 经一步反应首次不对称合成了具有重要药理活性 的三氟甲基取代吡咯啉和吡咯烷衍生物.

2013 年, Maruoka 等 ${ }^{[46]}$ 首次以价廉、易于操作的 $\mathrm{KCN}$ 为氰源, 在手性相转移催化剂作用下实现了不饱 和二酯的不对称共轭氰化(Eq. 20). 在环戊烷-水两相体 系中, 仅在 $2 \mathrm{~mol} \%$ 的双功能相转移催化剂 33 作用下, 一系列丙二酸二烷基酯顺利转化为相应产物. 当 $\mathrm{R}$ 为烷 

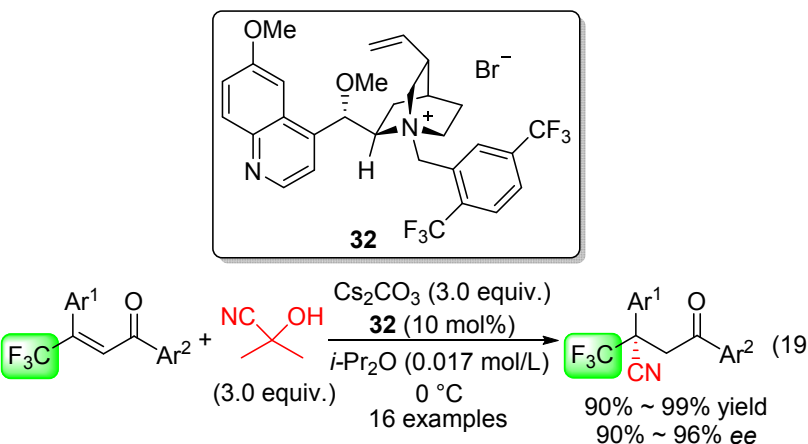

基时, 获得 64\% 86\%的产率和 88\% 93\%的 ee (如在一 $10{ }^{\circ} \mathrm{C}$ 反应, $e e$ 值可达 $95 \%$ ); 但 $\mathrm{R}$ 为 $\mathrm{Ph}$ 时，只有 $34 \%$ 的 产率和 $50 \%$ 的 ee 值. Brønsted 酸添加剂 $\mathrm{NH}_{4} \mathrm{Cl}$ 或 $\mathrm{HCl}$ 的使用对于提高反应速率至关重要. 此外, 如以 TMS$\mathrm{CN}$ 代替 $\mathrm{KCN}$ 作氰源, 则完全不反应. 研究表明, 双功 能催化剂的设计尤为关键, 33 和 $\mathrm{KCN}$ 作用得到氰铵盐 $\left(\mathrm{R}_{4} \mathrm{~N}^{+} \mathrm{CN}^{-}\right)$, 而着基能通过氢键稳定其中的氰根离子, 从而在进一步反应中实现良好的手性诱导; 如果将羟基 保护起来, 反应对映选择性很差.
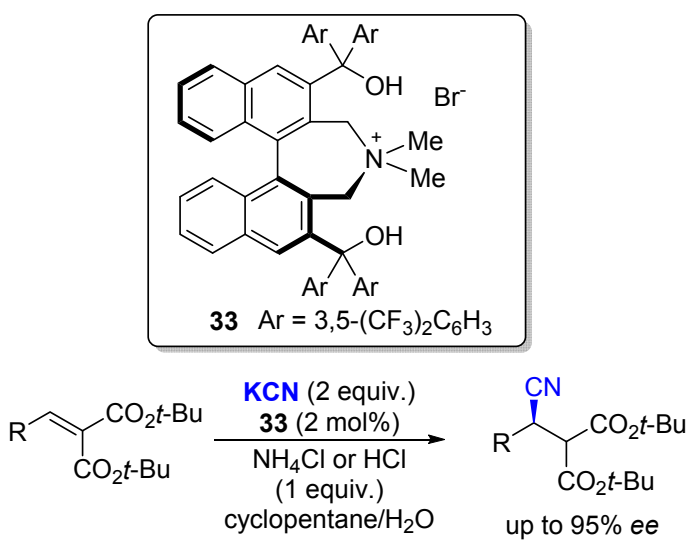

Maruoka 等的工作也是目前有机催化不对称共轭氰 化反应中催化剂用量最少的一例报道.

\section{3 总结与展望}

2003 年以来, $\alpha, \beta$-不饱和化合物的催化不对称共轭 氰化反应备受关注, 化学家们创造性地发展了一些金属 催化和有机催化新方法, 取得了极富意义的研究成果. 但是, 目前对这一反应研究还处于初级阶段, 尚存在使 用有毒氰源、催化剂活性普遍不高、受体底物有限、有 机催化方法研究不足、催化剂较为单一等问题，其应用 也还十分有限. 因此, 催化不对称共轭氧化反应研究依 然面临诸多挑战. 发展新的绿色无毒氰源、新的 Michael 受体、新的高效催化体系和新方法(尤其是有机催化方 法) 以及将其应用于新的 domino 反应和复杂分子的全合 成中将是今后不对称催化共轭氰化反应研究的主要方
向.

近年来, 我们课题组发展了以价廉无毒的亚铁氰化 钾为绿色氰源的 $\alpha, \beta$-不饱和羰基化合物的共轭氰化反应 方法 ${ }^{[47]}$, 但对其不对称催化反应研究尚在进行之中.

\section{References}

[1] For selected review, see: (a) Wang, W.; Liu, X.; Lin, L.; Feng, X. Eur. J. Org. Chem. 2010, 4751.

For representative examples, see: (b) Chen, F.-X.; Zhou, H.; Liu, X.; Qin, B.; Feng, X.; Zhang, G.; Jiang, Y. Chem. Eur. J. 2004, 10, 4790.

(c) Liu, X.; Qin, B.; Zhou, X.; He, B.; Feng, X. J. Am. Chem. Soc. 2005, 127, 12224 .

(d) Shen, K.; Liu, X.; Li, Q.; Feng, X. Tetrahedron 2008, 64, 147.

(e) Cao, J.-J.; Zhou, F.; Zhou, J. Angew. Chem., Int. Ed. 2010, 49, 4976.

[2] For selected review, see: (a) Liu, Y.-L.; Zhou, J. Synthesis 2015, 47, 1210.

(b) Wang, J.; Liu, X.; Feng, X. Chem. Rev. 2011, 111, 6947.

For representative examples, see: (c) Wang, J.; Hu, X.; Jiang, J.; Gou, S.; Huang, X.; Liu, X.; Feng, X. Angew. Chem., Int. Ed. 2007, $46,8468$.

(d) Wang, J.; Wang, W.; Li, W.; Hu, X.; Shen, K.; Tan, C.; Liu, X.; Feng, X. Chem. Eur. J. 2009, 15, 11642.

(e) Liu, Y.-L.; Zhou, F.; Cao, J.-J.; Ji, C.-B.; Ding, M.; Zhou, J. Org. Biomol. Chem. 2010, 8, 3847.

(f) Liu, Y.-L.; Shi, T.-D.; Zhou, F.; Zhao, X.-L.; Wang, X.; Zhou, J. Org. Lett. 2011, 13, 3826.

(g) Liu, Y.-L.; Zhou, J. Chem. Commun. 2013, 49, 4421

[3] Hegedus, L. S.; Cross, J. J. Org. Chem. 2004, 69, 8492.

[4] Winkler, M.; Knall, A. C.; Kulterer, M. R.; Klempier, N. J. Org. Chem. 2007, 72, 7423.

[5] Vázquez-Romero, A.; Rodríguez, J.; Lledó, A.; Verdaguer, X.; Riera, A. Org. Lett. 2008, 10, 4509.

[6] Nicolaou, K. C.; Stepan, A. F.; Lister, T.; Li, A.; Montero, A.; Tria, G. S.; Turner, C. I.; Tang, Y.; Wang, J.; Denton, R. M.; Edmonds, D. J. J. Am. Chem. Soc. 2008, 130, 13110.

[7] Rahman, S. M. A.; Ohno, H.; Maezaki, N.; Iwata, C.; Tanaka, T. Org. Lett. 2000, 2, 2893.

[8] Rahman, S. M. A.; Ohno, H.; Yoshino, H.; Satoh, N.; Tsukaguchi, M.; Murakami, K.; Iwata, C.; Maezaki, N.; Tanaka, T. Tetrahedron 2001, 57, 127.

[9] Mander, L. N.; Thomson, R. J. J. Org. Chem. 2005, 70, 1654.

[10] Muratake, H.; Natsume, M. Tetrahedron 2006, 62, 7071.

[11] Siwicka, A.; Cuperly, D.; Tedeschi, L.; Le Vézouët. R.; White, A. J. P.; Barrett, A. G. M. Tetrahedron 2007, 63, 5903.

[12] Fukuta, Y.; Mita, T.; Fukuda, N.; Kanai, M.; Shibasaki, M. J. Am. Chem. Soc. 2006, 128, 6312.

[13] Sammis, G. M.; Jacobsen, E. N. J. Am. Chem. Soc. 2003, 125, 4442.

[14] Mita, T.; Sasaki, K.; Kanai, M.; Shibasaki, M. J. Am. Chem. Soc. 2005, 127, 514.

[15] Dahuron, N.; Langlois, N. Synlett 1996, 51.

[16] Enders, D.; Syrig, R.; Raabe, G.; Fernández, R.; Gasch, C.; Lassaletta, J. M.; Llera, J.-M. Synthesis 1996, 48.

[17] Lassaletta, J. M.; Fernández, R.; MartínZamora, E.; Díez, E. J. Am. Chem. Soc. 1996, 118, 7002

[18] Sammis, G. M.; Danjo, H.; Jacobsen, E. N. J. Am. Chem. Soc. 2004, 126, 9928.

[19] Mazet, C.; Jacobsen, E. N. Angew. Chem., Int. Ed. 2008, 47, 1762.

[20] Madhavan, N.; Weck, M. Adv. Synth. Catal. 2008, 350, 419. 
[21] Madhavan, N.; Takatani, T.; Sherrill, C. D.; Weck, M. Chem. Eur. J. 2009, 15, 1186.

[22] Fujimori, I.; Mita, T.; Maki, K.; Shiro, M.; Sato, A.; Furusho, S.; Kanai, M.; Shibasaki, M. Tetrahedron 2007, 63, 5820.

[23] Morita, M.; Drouin, L.; Motoki, R.; Kimura, Y.; Fujimori, I.; Kanai, M.; Shibasaki, M. J. Am. Chem. Soc. 2009, 138, 3858.

[24] Tanaka, Y.; Kanai, M.; Shibasaki, M. J. Am. Chem. Soc. 2010, 132, 8862 .

[25] Sakaguchi, Y.; Kurono, N.; Yamauchi, K.; Ohkuma, T. Org. Lett. 2014, 16, 808 .

[26] Ohkuma, T.; Kurono, N. Synlett 2012, 23, 1865.

[27] Tanaka, Y.; Kanai, M.; Shibasaki, M. J. Am. Chem. Soc. 2008, 130, 6072.

[28] Yang, J.; Wang, Y.; Wu, S.; Chen, F.-X. Synlett 2009, 3365.

[29] Yang, J.; Chen, F.-X. Chin. J. Chem. 2010, 28, 981.

[30] Yang, J.; Shen, Y.; Chen, F.-X. Synthesis 2010, 1325.

[31] Yang, J.; Wu, S.; Chen, F.-X. Synlett 2010, 2725.

[32] Kurono, N.; Nii, N.; Sakaguchi, Y.; Uemura, M.; Ohkuma, T. Angew. Chem., Int. Ed. 2011, 50, 5541.

[33] Wang, Y.-F.; Zeng, W.; Sohail, M.; Guo, J.; Wu, S.; Chen, F.-X. Eur. J. Org. Chem. 2013, 4624.

[34] Zhang, J.; Liu, X.; Wang, R. Chem. Eur. J. 2014, $20,4911$.

[35] Wang, J.; Li, W.; Liu, Y.; Chu, Y.; Lin, L.; Liu, X.; Feng, X. Org. Lett. 2010, 12, 1280.

[36] Bernardi, L.; Fini, F.; Fochi, M.; Ricci, A. Synlett 2008, 1857.

[37] Bernal, P.; Fernández, R.; Lassaletta, J. M. Chem. Eur. J. 2010, 16, 7714.

[38] Lin, L.; Yin, W.; Fu, X.; Zhang, J.; Ma, X.; Wang, R. Org. Biomol. Chem. 2012, 10, 83

[39] North, M.; Watson, J. M. ChemCatChem 2013, 5, 2405.

[40] Jakhar, A.; Sadhukhan, A.; Khan, N.-u. H.; Saravanan, S.; Kureshy, R. I.; Abdi, S. H. R.; Bajaj, H. C. ChemCatChem 2014, 6, 2656.

[41] For selected reviews on asymmetric organocatalysis, see: (a) Dalko,
P. I.; Moisan, L. Angew. Chem., Int. Ed. 2001, 40, 3726.

(b) Dalko, P. I.; Moisan, L. Angew. Chem., Int. Ed. 2004, 43, 5138.

(c) Seayad, J.; List, B. Org. Biomol. Chem. 2005, 3, 719.

(d) List, B. Chem. Rev. 2007, 107, 5413.

(e) Dondoni, A.; Massi, A. Angew. Chem., Int. Ed. 2008, 47, 4638

(f) MacMillan, D. W. C. Nature 2008, 455, 304.

(g) Bertelsen, S.; Jørgensen, K. A. Chem. Soc. Rev. 2009, 38, 2178.

(h) Grondal, C.; Jeanty, M.; Enders, D. Nat. Chem. 2010, 2, 167.

(i) Chen, D.-F.; Han, Z.-Y.; Zhou, X.-L.; Gong, L.-Z. Acc. Chem. Res. 2014, 47, 2365.

[42] For review, see: Alemán, J.; Cabrera, S. Chem. Soc. Rev. 2013, 42, 774.

[43] For review, see: (a) Hashimoto, T.; Maruoka, K. Chem. Rev. 2007, 107,5656 .

(b) Ooi, T.; Maruoka, K. Angew. Chem., Int. Ed. 2007, 46, 4222.

(c) Jew, S.; Park, H. Chem. Commun. 2009, 7090.

(d) Brak, K.; Jacobsen, E. N. Angew. Chem., Int. Ed. 2013, 52, 534.

[44] Provencher, B. A.; Bartelson, K. J.; Liu, Y.; Foxman, B. M.; Deng, L. Angew. Chem., Int. Ed. 2011, 50, 10565.

[45] Kawai, H.; Okusu, S.; Tokunaga, E.; Sato, H.; Shiro, M.; Shibata, N. Angew. Chem., Int. Ed. 2012, 51, 4959.

[46] Liu, Y.; Shirakawa, S.; Maruoka, K. Org. Lett. 2013, 15, 1230.

[47] (a) Li, Z.; Liu, C.; Zhang, Y.; Li, R.; Ma, B.; Yang, J. Synlett 2012, 23, 2567.

(b) Li, Z.; Zhang, Y.; Wen, F.; Yin, J.; Zheng, H.; Li, H.; Yang, J. J. Chem. Res. 2013, 37, 601.

(c) Li, Z.; Yin, J.; Li, T.; Wen, G.; Shen, X.; Yang, J. Tetrahedron 2014, 70, 5619.

(d) Yang, J.; Zhan, B.; Ma, B.; Xiang, X.; Bao, Y.; Li, Z. Chin. J. Org. Chem. 2015, 35, 1286 (in Chinese).

(杨靖亚, 占宝华, 马奔, 向现成, 保云芬, 李政, 有机化学, 2015, 35, 1286.) 